\title{
Traumatic brain injury among female veterans: a review of sex differences in military neurosurgery
}

\author{
Lily H. Kim, BA,, Jennifer L. Quon, MD, ${ }^{1,2}$ Felicia W. Sun, BA, ${ }^{1,3}$ Kristen M. Wortman, PhD, ${ }^{1}$ \\ Maheen M. Adamson, $\mathrm{PhD}^{1,2}$ and Odette A. Harris, MD, MPH ${ }^{1,2}$

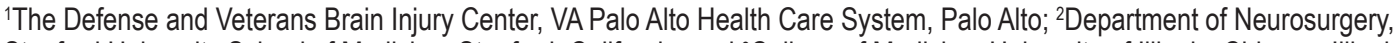 \\ Stanford University School of Medicine, Stanford, California; and ${ }^{3}$ College of Medicine, University of Illinois, Chicago, Illinois
}

\begin{abstract}
The impact of traumatic brain injury (TBI) has been demonstrated in various studies with respect to prevalence, morbidity, and mortality data. Many of the patients burdened with long-term sequelae of TBI are veterans. Although fewer in number, female veterans with TBI have been suggested to suffer from unique physical, mental, and social challenges. However, there remains a significant knowledge gap in the sex differences in TBI. Increased female representation in the military heralds an increased risk of TBI for female soldiers, and medical professionals must be prepared to address the unique health challenges in the face of changing demographics among the veteran TBI population. In this review, the authors aimed to present the current understanding of sex differences in TBI in the veteran population and suggest directions for future investigations.
\end{abstract}

https://thejns.org/doi/abs/10.3171/2018.9.FOCUS18369

KEYWORDS traumatic brain injury; concussion; female veteran; sex; review

$\mathrm{T}$ RAUMATIC brain injury (TBI) carries a high morbidity and mortality burden, with an estimated yearly incidence of 69 million people worldwide and 1.7 million in the United States..$^{17}$ TBI is divided into 3 categories (mild, moderate, and severe) based on the clinical and radiological severity ${ }^{45}$ While the survival rate is relatively high for those with mild and moderate TBI, patients may still suffer from substantial long-term sequelae of postconcussion syndrome, a complex disorder that may include headaches, dizziness, and psychological and behavioral symptoms. ${ }^{18}$ With this recognition, many studies in TBI research have focused on TBI rehabilitation and the recovery trajectory.

Neurosurgery plays a critical role in the management of TBI among military personnel, both in the acute stabilization of TBI during combat and the chronic rehabilitation process. ${ }^{4,65}$ Acutely, neurosurgeons can perform life-saving procedures such as a decompressive craniectomy that allow soldiers who have suffered serious head injuries an increased chance at survival and rehabilitation. ${ }^{4}$ However, even after successful acute management, the delayed con- sequences of TBI can be devastating, both medically and psychosocially. In a recent study, homeless veterans with a history of TBI had a significantly higher rate of psychiatric comorbidities and suicide risks than homeless veterans without a TBI history. ${ }^{6}$

Possibly owing to higher rates of participation in the military service and sports, men are twice as likely to sustain a TBI than women. ${ }^{8}$ Accordingly, the majority of research in TBI has been conducted on young men, and thus what we currently know about TBI is skewed. Little is known about women's experience of and recovery from TBI.

The number of women serving in the military has been gradually increasing. Recent statistics show that women across the Army, Marine Corps, Navy, and Air Force represent $20 \%$ of officers and $15 \%$ of enlisted personnel. ${ }^{40}$ Following the January 2013 Department of Defense (DOD) decision to unbar women from combat and combat units ${ }^{26}$ female veterans with TBI will likely increase in number in the coming years. In fact, female veterans have been known to have a risk of sustaining TBI that is similar to civilian men. ${ }^{56}$ However, the female experience of

ABBREVIATIONS DOD = Department of Defense; ICP = intracranial pressure; $P T S D=$ posttraumatic stress disorder; $T B I=$ traumatic brain injury; VA = Veterans Affairs. SUBMITTED August 1, 2018. ACCEPTED September 10, 2018.

INCLUDE WHEN CITING DOI: 10.3171/2018.9.FOCUS18369. 
TBI and recovery is only a burgeoning area of research. Women are a minority in the military and veteran communities, which creates unique challenges for recruiting female study participants and designing large-scale prospective studies that focus on female veterans. The dearth of research on this topic may also be a consequence of insufficient funding allocation. Search of the DOD Congressionally Directed Medical Research Programs database reveals only few funded sex-specific studies investigating trauma in female veterans, and none of them specifically has focused on TBI. ${ }^{12}$

In this review, we provide an overview of TBI in female veterans from a neurosurgical and rehabilitation perspective. We also explore relevant studies from the civilian neurosurgery and critical care literature with the aim of using our existing knowledge to better understand TBI in this underrepresented patient population.

\section{Methods}

To select studies for review, we performed a literature search using MEDLINE and Google Scholar. Reference lists in selected articles were also viewed to find any other relevant articles not identified by previous searches. A comprehensive literature search was performed using combinations of the following keywords as deemed appropriate: "female," "veteran," "gender," "sex," "traumatic brain injury," "concussion," "post-concussion syndrome," and "neurosurgery." We also took advantage of the MeSH database (("Brain Injuries, Traumatic”[Mesh] OR "PostConcussion Syndrome"[Mesh]) AND "Female"[Mesh] AND "Veterans"[Mesh] AND English[LA] NOT (letter[pt] OR news[pt] OR editorial[pt] OR comment[pt])) and Clinical Queries features of MEDLINE. When selecting articles, we excluded papers not translated into English and abstracts without a full article.

\section{Acute Neurosurgical Management}

Surgical management of severe TBI in military personnel dates back to World War I, when significant advances were made by Harvey Cushing, the "father of modern neurosurgery." 13 Techniques such as "thorough debridement" and primary dural closure were widely accepted in military neurosurgery as a result of Cushing's work, reducing the previous operative mortality rate by half. ${ }^{24}$ Where conservative management once predominated due to lack of access to specialized neurosurgical care, continued advancement in surgical approaches and expansion of resources now allow for more aggressive neurosurgical intervention, resulting in improved survival in this population. ${ }^{4}$ Emergency neurosurgical procedures are performed most often in the form of decompressive craniectomy to relieve intracranial pressure (ICP), with removal of unviable brain tissue or hematoma evacuation when indicated. Cranioplasty can be planned in an elective fashion after initial stabilization. 4,64

As women were previously not allowed to take active combat positions, injuries requiring emergency surgical treatment occurred almost exclusively in male military personnel. In a recent study that included a considerable number of veterans with severe TBI, some of whom may have required acute surgical intervention at the time of their initial injury, females constituted only $10 \%$ of the entire study population. ${ }^{39}$ Currently in the US, which is among the few countries that have lifted the ban, more women are assuming military combat roles. ${ }^{26,63}$ With this change, however, TBI in women will likely increase, making the impetus to predict their surgical outcomes compared to their male colleagues even more pressing.

Reflecting the imbalance in sex ratio, previous military neurosurgery literature has mostly studied the male population. One study conducted for soldiers in Operations Iraqi Freedom and Enduring Freedom included 408 patients with TBI, some of whom received decompressive craniectomy for the injury, but only 7 of the total subjects were women. ${ }^{4}$ In another study based on the United Kingdom military Joint Theater Trauma Registry, of 2785 military casualties from Iraq and Afghanistan during the 2004-2014 period, 39 (1\%) of them were female. ${ }^{64}$ Of the 14 patients who underwent craniectomy and cranioplasty in this study population, none were female.$^{64}$ Even in the civilian sector, craniectomy for severe TBI is more frequently performed in males, with studies reporting a male-to-female sex ratio that ranges from $3: 1$ to $4: 1 .^{46,47}$ However, the few women whose TBIs require decompressive craniectomy are twice as likely to experience postoperative complications from subsequent cranioplasty, such as infection, dural tear, and neurological deficits, compared to men undergoing the same procedure..$^{10}$

\section{Medical Management of TBI}

Female veterans are being managed based on evidence gathered from previous research studies whose participants were mostly or exclusively male..$^{28,31,32,34,66}$ Since the vast majority of military personnel who require neurosurgery for TBI have traditionally been men, when female soldiers require operations, their pre- and postoperative medical management is less evidence based. Medical literature in the field of military neurosurgery recognizes this sex imbalance as an area in need of improvement. In a study examining the characteristics of TBI caused by blast injuries in Iraq and Afghanistan wars, Mac Donald and colleagues considered their all-male study sample one of their study limitations. ${ }^{42}$

The sex disparity is also present in research on pharmacological agents used to treat severe TBI patients. Due to the considerable risk of posttraumatic seizure that can range from $4 \%$ to $25 \%$ when left untreated, patients with TBI are offered prophylactic antiepileptics. ${ }^{32}$ However, the selection of the most appropriate antiepileptic agent is debatable. Although early research favored the use of phenytoin for this patient population, a prospective trial conducted in 2012 showed that levetiracetam is not inferior to phenytoin in seizure prevention while foregoing the need for frequent drug-level monitoring. ${ }^{32}$ Following this trial, other studies similarly suggested the promising role of levetiracetam as the new agent of choice for posttraumatic seizure prophylaxis. ${ }^{59}$ However, these studies were conducted in a study population overrepresented by men, ${ }^{32,59}$ and clinicians may be left uncertain as to whether the same outcomes can be expected for women.

Appropriate pharmacological dosing of medications 
commonly used in neurosurgical care is of further concern. Many medications with indications in acute brain injury are dosed in a weight-based manner. A recent study showed that weight-based dosing of mannitol, used for patients with suspected high ICP, is more error prone in emergency situations. ${ }^{19}$ This suggests that female soldiers are potentially at a higher risk for overdose if their lower average body weight is not appropriately considered by medical providers accustomed to caring for male patients in emergency military settings.

We also lack the knowledge to determine appropriate neurocritical care parameters specifically for female military personnel, as the currently accepted ICP and cerebral perfusion pressure targets for TBI patients are based on male-predominant data. ${ }^{21}$ Evidence on female-specific parameters is sparse and inconclusive. A 2011 study conducted in 459 patients admitted for TBI proposes a lower ICP threshold of $18 \mathrm{~mm} \mathrm{Hg}$ for favorable outcome, suggesting that women with TBI may be less tolerant of intracranial hypertension. ${ }^{70}$ In contrast, a similarly designed study of patients with moderate and severe TBI argued otherwise, reporting a higher ICP threshold in women. ${ }^{54}$ In fact, women have been known to have higher cerebral perfusion at baseline than men. ${ }^{58}$ However, how this difference in healthy subjects should be accounted for when setting appropriate cerebral perfusion pressure or ICP thresholds among TBI patients in acute medical conditions is left largely undecided.

Regardless of the ideal threshold for each parameter, women are generally thought to have poorer cerebrovascular reactivity, implying a need for some degree of individualization of pressure goals based on the patient profile..$^{14,37}$ Women have also been shown to be more likely to have intracranial vascular injury following TBI, both for penetrating and closed-head injury, often in the form of traumatic aneurysm and subarachnoid hemorrhage. ${ }^{28,49}$ Given that women in general are known to be at an already higher risk for aneurysm formation and subsequent rupture, female veterans may be additionally susceptible to hemorrhagic cerebrovascular events due to the increased chance of acquiring TBI compared to nonmilitary women. ${ }^{35,41}$

Interestingly, in addition to increased risk for subarachnoid hemorrhage, female sex is also associated with hypercoagulability, leading to a higher likelihood of developing deep vein thrombosis and pulmonary embolism after TBI. ${ }^{67}$ In fact, TBI patients of both sexes are vulnerable to deep vein thrombosis and pulmonary embolism events, more so than those with other types of traumatic injuries, possibly due to the prolonged immobility and hypercoagulability as the body's mechanism to control hemorrhage. ${ }^{62}$ Oral contraceptive pill use is another female-specific risk factor that needs to be considered, particularly in the military population: with many soldiers opting to suppress menstruation during deployment, studies have shown higher oral contraceptive pill use in military personnel compared to the general female population. ${ }^{20,73}$

It should be noted, however, that these areas of concern primarily pertain to severe TBI that requires surgical and critical care management. Improvements in protective equipment, such as helmet and body armor, have decreased the incidence of severe TBI in the military. ${ }^{39}$
Severe TBI in veterans is now more likely to be due to motor vehicle collisions in noncombat settings rather than traditional combat trauma. ${ }^{39}$ With the majority of TBIs among veterans being classified as mild, chronic management of long-term complications is becoming increasingly more important. According to the most recent DOD/Defense and Veterans Brain Injury Center report published in 2018 , more than 15,000 of 17,707 total TBI cases in the US Army are considered mild. ${ }^{16}$ It is in these TBI cases of lower severity that we most frequently observe sex differences in the form of long-term disease sequelae. ${ }^{3}$

\section{Biological Differences}

Whether the sex difference in TBI experience has a biological explanation is an emerging topic of investigation. Since the late 1990s, female hormones such as estrogen and progesterone have been suggested to have a neuroprotective effect in animal models, facilitating the recovery phase of TBI by lowering ICP and improving cerebral perfusion. ${ }^{65,68}$ In fact, progesterone has been used in clinical trials for acute TBI patients with promising results of neurological improvement. ${ }^{74}$ Moreover, compared to male patients with TBI, female patients have been shown to have better-preserved uncinate fasciculus following the injury, which has been implicated in memory function..$^{22}$ The fact that women still experience similar or greater morbidity from TBI despite these potential neurobiological advantages may imply a larger role played by the environmental factors in their disease burden.

\section{TBI in Civilian Females}

The aforementioned risk factors may contribute to the increased mortality risk in female TBI patients compared to males as demonstrated in civilian studies, especially in children and postmenopausal women. ${ }^{18,52}$ Other findings contradict these studies, showing reduced mortality and complication rates for female TBI patients, ${ }^{5,57}$ including the postmenopausal group.$^{15}$ Others show no sex difference in mortality rates..$^{11,38,75}$

The sex-based morbidity data are equally varied. Women require shorter hospital stays, exhibit faster recovery, and retain more visual memory function..$^{50,69}$ In other domains of the post-TBI trajectory, women showed poorer outcomes. According to a meta-analysis performed in 2000 , women have a lower rate of returning to work and a higher degree of anxiety and/or depression. However, this meta-analysis was limited by the small scope (8 studies) and comparison of heterogeneous outcomes that ranged from mortality to functional performance and psychiatric symptoms. ${ }^{23}$ Multiple studies have also shown that women are more likely to suffer from postconcussion syndrome following mild TBI, experiencing a constellation of symptoms that range from chronic pain to emotional distur-

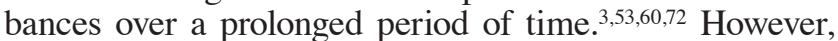
women are more proactive than men in seeking resources for rehabilitation, as shown with greater utilization of home health services among older women with TBI. ${ }^{25}$

Sex may be better understood as mediating symptom presentation rather than affecting the severity of disease burden. For example, in a review of studies that included 
women with mild TBI, female sex was more likely to be associated with postconcussive epilepsy and suicide. In contrast, more male patients were diagnosed with schizophrenia after TBI. ${ }^{9}$

Research to date on female TBI has primarily drawn on civilian samples. Application to veteran populations is challenging, mainly because of the different demographics and risk factors. For example, many studies in civilian samples include pediatric patients whose TBI experience may be significantly different from that of older military personnel and veterans. ${ }^{9,52,75}$ Moreover, the nature of injury often differs, as blast-related TBI is common among veterans, while motor vehicle collisions or falls predominate civilian TBI. ${ }^{29}$

\section{TBI in Female Veterans}

As in civilian samples, TBI symptomatology varies by sex among veterans. Among female veterans with mild TBI, there are more complaints related to somatosensory or vestibular symptoms than there are among male veterans within the first 30 months of injury. ${ }^{40}$ Female veterans with TBI also experience a wide range of nonspecific symptoms such as nausea, fatigue, appetite changes, and sleep disturbances.7 For reasons not clearly known, these symptoms seem to be less frequently reported by male veterans with mild or moderate TBI. In terms of chronic pain, female veterans are more likely to report headache and depression following TBI, whereas male veterans are more likely to report low-back pain after the injury. ${ }^{61}$

Although the inciting event of TBI may be a purely mechanical injury leading to structural damage, significant morbidity following the trauma stems from psychological or psychiatric sequelae. It has been found that female veterans have a higher incidence of posttraumatic stress disorders (PTSDs) independent of TBI.,66 The psychiatric burden among female veterans, including PTSD, does appear to play a role in how they experience and recover from TBI. In a 2008 survey of 2525 US Army soldiers with a mild TBI returning from Iraq, psychiatric comorbidities were significantly associated with more postconcussion symptoms. ${ }^{31}$

Instead of invoking the erroneous belief that women are "oversensitive," the high rate of PTSD among female veterans may be a reflection of the higher prevalence of military sexual trauma and intimate partner violence among female veterans. Women disproportionately experience military sexual trauma, with approximately one-third of all female veterans reported to have experienced military sexual trauma while on service compared to $1 \%$ of male veterans. ${ }^{43}$ In addition, female veterans are known to be at a higher risk of intimate partner violence than women in the general population, with almost one-fifth of female veterans screening positive for intimate partner violence. These forms of trauma not only contribute to the development of PTSD but also cause non-combat-related TBI in female veterans..$^{33}$

Despite having access to the Veterans Affairs (VA) health services, female veterans frequently underutilize the resource, a phenomenon that was recognized as early as the late $1990 \mathrm{~s} .{ }^{30}$ Approximately $80 \%-90 \%$ of VA mental health programs for veterans with TBI are being utilized by men. ${ }^{36,48}$ Although female veterans were more likely than their male counterparts to seek mental health services in general, most of them tend to visit non-VA health centers to receive the care. ${ }^{30}$ There may be a cyclical problem in meeting the needs of female veterans when their underrepresentation in the VA healthcare system itself challenges the appropriate level of research and resource allocation. Regardless, there is a need for more VA services that cater to female-specific needs, as lack thereof will only further deter female veterans from fully taking advantage of the VA healthcare system. This underutilization has implications not only for the management of TBI symptoms but also for the detection of TBI among female veterans. According to a VA study of 465 veterans, women are 3 times less likely to complete comprehensive TBI evaluation, ${ }^{44}$ potentially hindering timely screening and treatment.

\section{TBI in Male Veterans}

While the TBI profile of female veterans highlighted in the previous section may be distinct from that of their male counterparts, this is not to understate the difficulties male veterans with this condition also face. Although lower than in women, male veterans with TBI have a higher rates of PTSD and depression than are seen in the general population. ${ }^{51}$ Although female veterans may have higher rates of psychological or psychiatric symptoms from TBI than male veterans, male veterans who do have such symptoms may be less likely to seek professional help. ${ }^{1}$ Men tend to be reluctant to ask for and receive professional help for psychological or psychiatric issues, a phenomenon that is commonly reinforced by cultural expectations of masculinity. ${ }^{1}$ Younger males are the least likely to seek resources for psychological support, ${ }^{55}$ a particular obstacle in TBI management given that this age group has the highest TBI incidence.

Regardless of sex, veterans with TBI face challenges when seeking employment as they reintegrate into the civilian society. However, the potential hindrances to their successful employment may have sex differences. In a recent study, male veterans with TBI were less likely to be employed if older, less educated, and depressed. ${ }^{2}$ In the same study, moderate or severe TBI (in contrast to mild TBI), comorbid PTSD, and drug abuse also predicted unemployment in male veterans. In contrast, the only significant risk factor for unemployment among female veterans included in this study was the presence of affective or cognitive symptoms. ${ }^{2}$ Other potential barriers to successful integration back into civilian society specific to men include a significantly higher risk of developing a comorbid substance use disorder ${ }^{27,61}$ and dementia following the injury. ${ }^{71}$ This suggests that male and female veterans may need different, targeted resources to facilitate employment.

\section{Conclusions}

A review of the currently available literature on the topic of TBI and sex differences in the veteran population revealed that women are less likely than men to sustain a TBI and require emergency craniectomy. However, female veterans are also more likely to experience long-term postconcussion syndrome and to opt for non-VA health servic- 
es. Moreover, female veterans with TBI may be managed based on evidence drawn from previous studies in which their sex was not well represented.

As women's contribution to the military garners increasing attention, so too must the unique challenges they face during and after service. In the field of neurosurgery, the sex differences in TBIs are only starting to be recognized. Evidence suggests that women who have served in the military may have different postconcussion symptoms from their male counterparts and that psychosocial factors may compound their disease burden. The sex differences implied by different studies and summarized in the current article, however, should neither be used to justify a hasty generalization that overlooks individual presentations nor to perpetuate the traditional bias that women are "difficult" patients. Robust prospective studies involving sizable numbers of female veterans with TBI are lacking due to multiple factors, including a lower incidence of TBI in females, the minority status of women in the military, and potential barriers to funding. More research, greater attention, and appropriate action are critical to prevent overgeneralized medical practices and beliefs from becoming another source of inequality in this underrepresented population. Such effort, however, will only be possible with improved resource allocation, which calls for support from research funding agencies that recognize TBI in female veterans as an important issue of health disparity.

\section{References}

1. Addis ME, Mahalik JR: Men, masculinity, and the contexts of help seeking. Am Psychol 58:5-14, 2003

2. Amara JH, Stolzmann KL, Iverson KM, Pogoda TK: Predictors of employment status in male and female post-9/11 veterans evaluated for traumatic brain injury. J Head Trauma Rehabil [epub ahead of print], 2018

3. Bazarian JJ, Blyth B, Mookerjee S, He H, McDermott MP: Sex differences in outcome after mild traumatic brain injury. J Neurotrauma 27:527-539, 2010

4. Bell RS, Mossop CM, Dirks MS, Stephens FL, Mulligan L, Ecker R, et al: Early decompressive craniectomy for severe penetrating and closed head injury during wartime. Neurosurg Focus 28(5):E1, 2010

5. Berry C, Ley EJ, Tillou A, Cryer G, Margulies DR, Salim A: The effect of gender on patients with moderate to severe head injuries. J Trauma 67:950-953, 2009

6. Brenner LA, Hostetter TA, Barnes SM, Stearns-Yoder KA, Soberay KA, Forster JE: Traumatic brain injury, psychiatric diagnoses, and suicide risk among veterans seeking services related to homelessness. Brain Inj 31:1731-1735, 2017

7. Brickell TA, Lippa SM, French LM, Kennedy JE, Bailie JM, Lange RT: Female service members and symptom reporting after combat and non-combat-related mild traumatic brain injury. J Neurotrauma 34:300-312, 2017

8. Bruns J Jr, Hauser WA: The epidemiology of traumatic brain injury: a review. Epilepsia 44 (s10):2-10, 2003

9. Cancelliere C, Donovan J, Cassidy JD: Is sex an indicator of prognosis after mild traumatic brain injury: a systematic analysis of the findings of the World Health Organization Collaborating Centre Task Force on Mild Traumatic Brain Injury and the International Collaboration on Mild Traumatic Brain Injury Prognosis. Arch Phys Med Rehabil 97 (2 Suppl):S5-S18, 2016

10. Chaturvedi J, Botta R, Prabhuraj AR, Shukla D, Bhat DI, Devi BI: Complications of cranioplasty after decompressive craniectomy for traumatic brain injury. Br J Neurosurg 30:264-268, 2016

11. Coimbra R, Hoyt DB, Potenza BM, Fortlage D, Hollingsworth-Fridlund P: Does sexual dimorphism influence outcome of traumatic brain injury patients? The answer is no! J Trauma 54:689-700, 2003

12. Congressionally Directed Medical Research Programs: Transforming Healthcare through Innovative and Impactful Research. Fort Detrick, MD: Department of Defense, 2015 (http://cdmrp.army.mil/search.aspx) [Accessed October 3, 2018]

13. Cushing H: Notes on penetrating wounds of the brain. BMJ 1:221-226, 1918

14. Czosnyka M, Radolovich D, Balestreri M, Lavinio A, Hutchinson P, Timofeev I, et al: Gender-related differences in intracranial hypertension and outcome after traumatic brain injury. Acta Neurochir Suppl (Wien) 102:25-28, 2008

15. Davis DP, Douglas DJ, Smith W, Sise MJ, Vilke GM, Holbrook TL, et al: Traumatic brain injury outcomes in pre- and post- menopausal females versus age-matched males. J Neurotrauma 23:140-148, 2006

16. Defense and Veterans Brain Injury Center: 2017 (Q1-Q4) DoD TBI Worldwide Numbers. Falls Church, VA: DVBIC, 2018 (http://dvbic.dcoe.mil/files/tbi-numbers/worldwidetotals-2000-2018Q1-total_jun-21-2018_v1.0_2018-07-26_0. pdf) [Accessed October 3, 2018]

17. Dewan MC, Rattani A, Gupta S, Baticulon RE, Hung YC, Punchak M, et al: Estimating the global incidence of traumatic brain injury. J Neurosurg [epub ahead of print April 27, 2018. DOI: 10.3171/2017.10.JNS17352]

18. Dischinger PC, Ryb GE, Kufera JA, Auman KM: Early predictors of postconcussive syndrome in a population of trauma patients with mild traumatic brain injury. J Trauma 66:289-297, 2009

19. Elliott CA, MacKenzie M, O’Kelly CJ: Mannitol dosing error during interfacility transfer for intracranial emergencies. J Neurosurg 123:1166-1169, 2015

20. Enewold L, Brinton LA, McGlynn KA, Zahm SH, Potter JF, Zhu K: Oral contraceptive use among women in the military and the general U.S. population. J Womens Health (Larchmt) 19:839-845, 2010

21. Eun J, Huh J, Yang SY, Huh HY, Ahn JK, Cho KW, et al: Determining the lower limit of cerebral perfusion pressure in patients undergoing decompressive craniectomy following traumatic brain injury. World Neurosurg 111:e32-e39, 2018

22. Fakhran S, Yaeger K, Collins M, Alhilali L: Sex differences in white matter abnormalities after mild traumatic brain injury: localization and correlation with outcome. Radiology 272:815-823, 2014

23. Farace E, Alves WM: Do women fare worse? A metaanalysis of gender differences in outcome after traumatic brain injury. Neurosurg Focus 8(1):e6, 2000

24. Gilhooly J, Siu A, Beare M, Ecklund JM: Acute management of military-related injury. Handb Clin Neurol 127:379-393, 2015

25. Graham JE, Radice-Neumann DM, Reistetter TA, Hammond FM, Dijkers M, Granger CV: Influence of sex and age on inpatient rehabilitation outcomes among older adults with traumatic brain injury. Arch Phys Med Rehabil 91:43-50, 2010

26. Greeves JP: Physiological implications, performance assessment and risk mitigation strategies of women in combat-centric occupations. J Strength Cond Res 29 (Suppl 11):S94S100, 2015

27. Grossbard J, Malte CA, Lapham G, Pagulayan K, Turner AP, Rubinsky AD, et al: Prevalence of alcohol misuse and follow-up care in a national sample of OEF/OIF VA patients with and without TBI. Psychiatr Serv 68:48-55, 2017

28. Haddad FS, Haddad GF, Taha J: Traumatic intracranial an- 
eurysms caused by missiles: their presentation and management. Neurosurgery 28:1-7, 1991

29. Hawley CA, de Burgh HT, Russell RJ, Mead A: Traumatic brain injury recorded in the UK Joint Theatre Trauma Registry among the UK armed forces. J Head Trauma Rehabil 30:E47-E56, 2015

30. Hoff RA, Rosenheck RA: The use of VA and non-VA mental health services by female veterans. Med Care 36:1524-1533, 1998

31. Hoge CW, McGurk D, Thomas JL, Cox AL, Engel CC, Castro CA: Mild traumatic brain injury in U.S. soldiers returning from Iraq. N Engl J Med 358:453-463, 2008

32. Inaba K, Menaker J, Branco BC, Gooch J, Okoye OT, Herrold $\mathrm{J}$, et al: A prospective multicenter comparison of levetiracetam versus phenytoin for early posttraumatic seizure prophylaxis. J Trauma Acute Care Surg 74:766-773, 2013

33. Iverson KM, Pogoda TK: Traumatic brain injury among women veterans: an invisible wound of intimate partner violence. Med Care 53 (4 Suppl 1):S112-S119, 2015

34. Jackson CE, Green JD, Bovin MJ, Vasterling JJ, Holowka DW, Ranganathan G, et al: Mild traumatic brain injury, PTSD, and psychosocial functioning among male and female U.S. OEF/OIF veterans. J Trauma Stress 29:309-316, 2016

35. Kongable GL, Lanzino G, Germanson TP, Truskowski LL, Alves WM, Torner JC, et al: Gender-related differences in aneurysmal subarachnoid hemorrhage. J Neurosurg 84:4348,1996

36. Lawrence KA, Matthieu MM, Robertson-Blackmore E: Completion of a veteran-focused civic service program improves health and psychosocial outcomes in Iraq and Afghanistan veterans with a history of traumatic brain injury. Mil Med 182:e1763-e1770, 2017

37. Lazaridis C, DeSantis SM, Smielewski P, Menon DK, Hutchinson P, Pickard JD, et al: Patient-specific thresholds of intracranial pressure in severe traumatic brain injury. $\mathbf{J}$ Neurosurg 120:893-900, 2014

38. Leitgeb J, Mauritz W, Brazinova A, Janciak I, Majdan M, Wilbacher I, et al: Effects of gender on outcomes after traumatic brain injury. J Trauma 71:1620-1626, 2011

39. Licona NE, Chung JS, Poole JH, Salerno RM, Laurenson NM, Harris OA: Prospective tracking and analysis of traumatic brain injury in veterans and military personnel. Arch Phys Med Rehabil 98:391-394, 2017

40. Lippa SM, Brickell TA, Bailie JM, French LM, Kennedy JE, Lange RT: Postconcussion symptom reporting after mild traumatic brain injury in female service members: impact of gender, posttraumatic stress disorder, severity of injury, and associated bodily injuries. J Head Trauma Rehabil 33:101112,2018

41. Longstreth WT Jr, Koepsell TD, Yerby MS, van Belle G: Risk factors for subarachnoid hemorrhage. Stroke 16:377385,1985

42. Mac Donald CL, Johnson AM, Cooper D, Nelson EC, Werner NJ, Shimony JS, et al: Detection of blast-related traumatic brain injury in U.S. military personnel. N Engl J Med 364:2091-2100, 2011

43. Maguen S, Cohen B, Ren L, Bosch J, Kimerling R, Seal K: Gender differences in military sexual trauma and mental health diagnoses among Iraq and Afghanistan veterans with posttraumatic stress disorder. Womens Health Issues 22:e61-e66, 2012

44. Maguen S, Lau KM, Madden E, Seal K: Factors associated with completing comprehensive traumatic brain injury evaluation. Mil Med 177:797-803, 2012

45. Management of Concussion/mTBI Working Group: VA/DoD clinical practice guideline for management of concussion/ mild traumatic brain injury. J Rehabil Res Dev 46:CP1CP68, 2009

46. Meier U, Gräwe A: The importance of decompressive cra- niectomy for the management of severe head injuries. Acta Neurochir Suppl 86:367-371, 2003

47. Meier U, Zeilinger FS, Henzka O: The use of decompressive craniectomy for the management of severe head injuries. Acta Neurochir Suppl 76:475-478, 2000

48. Miles SR, Harik JM, Hundt NE, Mignogna J, Pastorek NJ, Thompson KE, et al: Delivery of mental health treatment to combat veterans with psychiatric diagnoses and TBI histories. PLoS One 12:e0184265, 2017

49. Miley JT, Rodriguez GJ, Qureshi AI: Traumatic intracranial aneurysm formation following closed head injury. J Vasc Interv Neurol 1:79-82, 2008

50. Moore DW, Ashman TA, Cantor JB, Krinick RJ, Spielman LA: Does gender influence cognitive outcome after traumatic brain injury? Neuropsychol Rehabil 20:340-354, 2010

51. Morissette SB, Woodward M, Kimbrel NA, Meyer EC, Kruse MI, Dolan S, et al: Deployment-related TBI, persistent postconcussive symptoms, PTSD, and depression in OEF/OIF veterans. Rehabil Psychol 56:340-350, 2011

52. Munivenkatappa A, Agrawal A, Shukla DP, Kumaraswamy D, Devi BI: Traumatic brain injury: does gender influence outcomes? Int J Crit Illn Inj Sci 6:70-73, 2016

53. Nampiaparampil DE: Prevalence of chronic pain after traumatic brain injury: a systematic review. JAMA 300:711-719, 2008

54. Nourallah B, Zeiler FA, Calviello L, Smielewski P, Czosnyka M, Menon DK: Critical thresholds for intracranial pressure vary over time in non-craniectomised traumatic brain injury patients. Acta Neurochir (Wien) 160:1315-1324, 2018

55. Oliver MI, Pearson N, Coe N, Gunnell D: Help-seeking behaviour in men and women with common mental health problems: cross-sectional study. Br J Psychiatry 186:297301, 2005

56. Ommaya AK, Ommaya AK, Dannenberg AL, Salazar AM: Causation, incidence, and costs of traumatic brain injury in the U.S. military medical system. J Trauma 40:211-217, 1996

57. Ottochian M, Salim A, Berry C, Chan LS, Wilson MT, Margulies DR: Severe traumatic brain injury: is there a gender difference in mortality? Am J Surg 197:155-158, 2009

58. Parkes LM, Rashid W, Chard DT, Tofts PS: Normal cerebral perfusion measurements using arterial spin labeling: reproducibility, stability, and age and gender effects. Magn Reson Med 51:736-743, 2004

59. Patanwala AE, Kurita A, Truong E: Low-dose levetiracetam for seizure prophylaxis after traumatic brain injury. Brain Inj 30:156-158, 2016

60. Preiss-Farzanegan SJ, Chapman B, Wong TM, Wu J, Bazarian JJ: The relationship between gender and postconcussion symptoms after sport-related mild traumatic brain injury. PM R 1:245-253, 2009

61. Pugh MJ, Finley EP, Wang CP, Copeland LA, Jaramillo CA, Swan AA, et al: A retrospective cohort study of comorbidity trajectories associated with traumatic brain injury in veterans of the Iraq and Afghanistan wars. Brain Inj 30:1481-1490, 2016

62. Reiff DA, Haricharan RN, Bullington NM, Griffin RL, McGwin G Jr, Rue LW III: Traumatic brain injury is associated with the development of deep vein thrombosis independent of pharmacological prophylaxis. J Trauma 66:1436-1440, 2009

63. Resnick EM, Mallampalli M, Carter CL: Current challenges in female veterans' health. J Womens Health (Larchmt) 21:895-900, 2012

64. Roberts SA, Toman E, Belli A, Midwinter MJ: Decompressive craniectomy and cranioplasty: experience and outcomes in deployed UK military personnel. Br J Neurosurg 30:529_ 535, 2016

65. Roof RL, Duvdevani R, Heyburn JW, Stein DG: Progester- 
one rapidly decreases brain edema: treatment delayed up to 24 hours is still effective. Exp Neurol 138:246-251, 1996

66. Schneiderman AI, Braver ER, Kang HK: Understanding sequelae of injury mechanisms and mild traumatic brain injury incurred during the conflicts in Iraq and Afghanistan: persistent postconcussive symptoms and posttraumatic stress disorder. Am J Epidemiol 167:1446-1452, 2008

67. Schreiber MA, Differding J, Thorborg P, Mayberry JC, Mullins RJ: Hypercoagulability is most prevalent early after injury and in female patients. J Trauma 58:475-481, 2005

68. Shahrokhi N, Khaksari M, Soltani Z, Mahmoodi M, Nakhaee N: Effect of sex steroid hormones on brain edema, intracranial pressure, and neurologic outcomes after traumatic brain injury. Can J Physiol Pharmacol 88:414-421, 2010

69. Slewa-Younan S, Baguley IJ, Heriseanu R, Cameron ID, Pitsiavas V, Mudaliar Y, et al: Do men and women differ in their course following traumatic brain injury? A preliminary prospective investigation of early outcome. Brain Inj 22:183-191, 2008

70. Sorrentino E, Diedler J, Kasprowicz M, Budohoski KP, Haubrich C, Smielewski P, et al: Critical thresholds for cerebrovascular reactivity after traumatic brain injury. Neurocrit Care 16:258-266, 2012

71. Starkstein SE, Jorge R: Dementia after traumatic brain injury. Int Psychogeriatr 17 (Suppl 1):S93-S107, 2005

72. Styrke J, Sojka P, Björnstig U, Bylund PO, Stålnacke BM: Sex-differences in symptoms, disability, and life satisfaction three years after mild traumatic brain injury: a populationbased cohort study. J Rehabil Med 45:749-757, 2013

73. Trego LL: Military women's menstrual experiences and interest in menstrual suppression during deployment. J Obstet Gynecol Neonatal Nurs 36:342-347, 2007

74. Xiao G, Wei J, Yan W, Wang W, Lu Z: Improved outcomes from the administration of progesterone for patients with acute severe traumatic brain injury: a randomized controlled trial. Crit Care 12:R61, 2008
75. Yeung JH, Mikocka-Walus AA, Cameron PA, Poon WS, Ho $\mathrm{HF}$, Chang A, et al: Protection from traumatic brain injury in hormonally active women vs men of a similar age: a retrospective international study. Arch Surg 146:436-442, 2011

\section{Disclosures}

The authors report no conflict of interest concerning the materials or methods used in this study or the findings specified in this paper.

\section{Author Contributions}

Conception and design: Adamson, Kim, Quon, Harris. Acquisition of data: Adamson, Kim, Sun. Analysis and interpretation of data: Adamson, Kim, Quon. Drafting the article: Kim, Quon. Critically revising the article: Adamson, Kim, Quon, Sun, Wortman. Reviewed submitted version of manuscript: all authors. Approved the final version of the manuscript on behalf of all authors: Adamson. Administrative/technical/material support: Kim. Study supervision: Adamson, Harris.

\section{Supplemental Information \\ Videos \\ Video Abstract. https://vimeo.com/298584617.}

\section{Correspondence}

Maheen M. Adamson: Stanford University School of Medicine, Defense and Veterans Brain Injury Center, VA Palo Alto Health Care System, Palo Alto, CA.madamson@stanford.edu. 